\title{
EXPERIENCES OF ENTERPRISE RESOURCE PLANNING SYSTEM AT A FLAGSHIP UNIVERSITY IN AFRICA: \\ FAMILIARITY, BARRIERS AND WAY FORWARD
}

\author{
B. Brown \\ Dean for Faculty of Business and Leisure \\ University of Derby in Botswana and \\ Botswana Accountancy College \\ Gaborone, Botswana \\ e-mail: byronb@bac.ac.bw and bbrown7019@gmail.com
}

\section{R. Mooketsi}

Student Administration

University of Botswana

Gaborone, Botswana

e-mail: mooketsi@mopipi.ub

\section{ABSTRACT}

Recent research has discussed the difficulties with implementing ERP systems, and the opportunities associated with the use of these systems in university contexts, but has not examined the experiences that internal stakeholders, particularly in African contexts puzzled by certain technology, have with these systems in the period after the systems "go-live". This study explored these experiences, at one Flagship University in Botswana. Students, academic and administrative staff were surveyed about their familiarity with using the ERP system and the barriers they faced. Additional qualitative data probed into motives for ERP system use and concerns thereof. Findings revealed that the stakeholders showed high familiarity with, and usage of, the ERP modules tailored to their particular needs. The motives for use were mainly related to management efficiency and customer satisfaction, but not information accuracy. Information inaccuracy was an obstacle, along with academic and administrative staff relapse into old habits, weaknesses in the transitional change management, a detached persona of the university administration, and inadequate training/support, particularly for stakeholders who were not part of the system development. The gravest barriers were experienced these stakeholders. Importantly, the study offered insights into how the barriers and concerns held can be mitigated.

Keywords: ERP systems; ERP familiarity; ERP barriers; Higher Education; University; Botswana

\section{INTRODUCTION}

Over recent decades, universities globally have joined business organizations in implementing enterprise resource planning (ERP) systems (Noaman and Ahmed 2015; Ndungu and Kyalo 2015; Swartz and Orgill 2012; King, Kvavik and Voloudakis 2002; Koch and Mitteregger 
2016). The incentives for universities across the globe and in Africa in particular to go this route are diverse. Typically, these impetuses, for example, are the ongoing decline in government funding for students in Africa, gradual spike in competition among higher education institutions, tighter regulations by higher education authority, changes in the needs of students, growth in the demand for higher education, and fluctuating expectations of employers and industry stakeholders. These changes have created a need more efficient management processes in universities which the ERP system purported to offer (Al-Mashari 2003; Rabaa’i 2009).

Universities in small African States like Botswana are catching on with universities elsewhere in Africa and across the world by adopting ERP (Mooketsi 2015). We have seen from past inquiries that an ERP technology provides universities with an integrated information system that connects faculties and corporate services functions across the enterprise (Koch and Mitteregger 2016; King et al. 2002). ERP systems in higher education is multiple in scope i.e., being able to track a variety of activities, including undertakings that fall in management, financial and student administration (Noaman and Ahmed 2015). A fully used ERP system can assist a university to enhance its operational efficiency because workflow is enjoined and the flow of information across the different parts of the institution gets easier to manage (Koch and Mitteregger 2016). The effects of enhanced efficiency for the university are diverse, including elevated stakeholder satisfaction, tighter controls, accurate information, and lower running costs (Noaman and Ahmed 2015; Ndungu and Kyalo 2015; Swartz and Orgill 2012; King et al. 2002).

In Botswana, the country’s flagship university invested a significant amount of money to procure an ERP system, and has spent considerable resources implementing it, yet the institution finds itself operating a parallel manual system, as its internal stakeholders perform certain tasks on the installed ERP system but occasionally switch to the manual system to do other tasks. In other words, it is doubtful that the university is fully maximizing the ERP system capabilities. This observation is made at a time when the ERP literature shows that organizations utilize less than 70 per cent of the ERP system capabilities (Chou et al. 2014; King et al. 2002); organizations experience a rate of between 65 and 85 per cent failure of ERP systems (King et al. 2002; Rouhani and Ravasan 2013); organizations receive less than 35 per cent of the promised benefits (Swartz and Orgill 2012; Rouhani and Ravasan 2013). There is a gap in the literature on internal stakeholders' experiences of enterprise-resource-planning system in higher education institutions in the period after ERP "go-live”. This inquiry therefore focuses on this issue, and specifically assesses the extent university internal stakeholders (i.e., students, academic and administrative staff) maximize the use of the ERP system, the barriers 
and concerns they have, and strategies to minimize these challenges. Outcomes on these can help guide efforts to boost optimization of the system.

\section{CONCEPTUAL FRAMEWORK}

In a university context, the main users of an ERP system are its internal stakeholders - herein defined as students, academic and administrative staff. While each of these stakeholder groups utilises the ERP technology for different purposes generally, they collectively feed data into the university system for resources planning, enterprise-wide. ERP assimilates functions across the university into a solitary system that sustain the organization's transactions and processes as they relate to finance, human resources, and student service (King et al. 2002). ERP users act in the manner designed by the university. Consequently, the user participation theory, along with the technology acceptance model, can serve as a conceptual framework to assess the issues that can affect a university's optimal utilization of its ERP system.

Barki and Hartwick (1994) developed the user participation theory in the early 1990s. Its basic premise is that level of use, acceptance, appreciation, knowledge, and so on of an information technology system such as the ERP depends on the degree that its users participated in the development and deployment of the system (Barki and Hartwick 1994; De Waal and Batenburg 2014). This theory directs us to look back at the preliminary stages of planning and preparation for the technology and trace the issues from there straight to where the actual deployment and "go-live" of the system has been done. User involvement in the process is pivotal but the participation is not a mere add on; it must be meaningful and reflects certain attributes. The theory demands that the university pays attention to: (i) the type of participation (i.e., having actual users versus user representatives); (ii) the extent of participation (i.e., participating in all stages versus one at the end); (iii) content of participation (i.e., the type of contribution - technical/functional experts; change champions); (iv) degree of responsibility (i.e., user's role and its level during the process); (v) the formality of the participation (i.e., participating in official and formal sessions versus casual discussions); and (vi) level of influence (i.e., taking user's suggestions/inputs on board versus dismissing them) (Bano and Zowghi 2015; Cavaye 1995). These attributes provide hints of ways to boost the usage of the ERP system. Furthermore, although past research corroborates the link which the theory propagates between the participation of users in ERP process and level of usage (De Waal and Batenburg 2014), Markus and Mao (2004) cautioned that emphasis ought to be placed on the quality as opposed to the quantity of participation since the depth and richness of the engagement has the greatest influence on action. 
But psychologists argue that beyond the notion of opportunity to participate, and the depth thereof, human behaviour, i.e., to use or not use a system, is influenced by their perception (Davis 1989; Kwak, Park, Chung and Ghosh 2012). The technology acceptance model suggests the perception of students, academic and administrative staff within the university can affect their behavioural intention to use the ERP system. Based on this model, Kwak et al. (2012) assert that two forces impact the optimal use of ERP system: (a) its perceived usefulness, and (b) its perceived ease of use (Kwak et al. 2012). If the system is perceived as complicated, and useless, the students, academic and administrative staff may be put off, and they may resort to old, tried and tested ways of doing things. The internal stakeholders must therefore be satisfied with the system, and show familiarity with it. They must be satisfied that by using it, they can achieve greater efficiency, better job performance, and that it will not be a burden to them, and so on (Sadki et al. 2015). It is clear then that a range of factors can shape how ERP system is experienced in a university, and whether it is optimally used, after the "green light" to operate has been given. Thus, the tenets of both the user participation theory and the technology acceptance model offer broad guidelines for this study by identifying and defining central ERP usage concepts. The study thus explores the experiences that students, academic and administrative staff have of ERP at a flagship university in Botswana, with emphasis on their level of familiarity, and any barriers and concerns they hold. Three objectives guided the study.

\section{OBJECTIVES OF THE STUDY}

The purpose of the study gives rise to the following objectives:

1. To examine internal stakeholders' experiences with the use of ERP system, in terms of their familiarity and use of it;

2. To examine possible motives for using of ERP system;

3. To explore possible barriers encountered and/or concerns held as they utilize the ERP system, and possible measures to improve the situation.

\section{LITERATURE REVIEW}

\section{ERP system}

As a concept coined in the 1990s, enterprise resource planning (ERP) is a computer-based, multiple modules software solution, which assimilates information and business processes (Koch 2002; Yelken 2005; Maas, Van Fenema and Soeters 2014). Among the common vendors 
of ERP system are Oracle, PeopleSoft, SAP and SCT (Banner). As expressed by Koch (2002), the critical term in ERP is "enterprise" because it is designed as a packaged application to harmonize the functions of the whole organisation into a single system which permits sharing of information all over the enterprise once it is entered into a database. This means, an ERP system is not a proprietary application developed for a single unique customer (Maas et al., 2014) but rather is a complete application suite that can be used in several different enterprises (Althonayan 2013; Charisma 2014).

In a recent comprehensive study of ERP in higher education in the Kingdom of Saudi Arabia (Noaman and Ahmed 2015), the researchers admitted that the scope of ERP system in higher education has expanded from the mere back-office functions such as order financial management, asset management, general management, and human resources management (Swartz and Orgill 2012), to include more applications such as marketing, student systems, management of grants, and e-commerce. Other studies also show that features of ERP systems include supply chain systems (Althonayan 2013; Charisma 2014). This implies that universities adopting ERP systems have a diverse range of functionalities to include as module combinations. However, not all functionalities are used. King et al.'s (2002) survey of 480 universities and colleges with completed ERP systems around the world, found that the most common ERP module combinations they adopted were the HR, finance, and the student record administration module. A further interesting evidence from King et al.'s study was that twothirds of those institutions that have implemented ERP system continued to use their existing legacy systems as well. The finding affirms the overall underuse of ERP systems.

\section{Influences on ERP system usage}

The literature on ERP usage is diverse, and focused heavily on non-educational institutions. Nevertheless, in terms of the theories that underpin this study, and the literature generally, five key influences on the use of ERP system in organisations, generally can be identified: i.e., the degree of satisfaction of the user; their level of participation, involvement, and preparation; as well as their attitude and satisfaction with the system (Bano and Zowghi 2015; Cavaye 1995; De Waal and Batenburg 2014; Davis 1989; Kwak et al. 2012; Sadki et al. 2015).

Participation: Past studies illustrate that user adoption and utilization of an ERP system can be elevated by increasing their level of participation in the ERP development process (Barki and Hartwick 1994). A university which provide deep and enriched participation during the initiation and development phase of the system stands a better chance to witness high degree of usage after the system "go-live” (Poonam and Agarwal 2014). Qureshi and Abdulkhalaq (2015) 
stressed the significance of user participation, and suggest that the building of employee skills set through training is key strategy to guarantee high participation. The earlier the involvement of users in the process the better because they are then able to develop a clear understanding of processes (Poonam and Agarwal 2014). Mahdavian and Mostajeran (2013) maintain that the inclusion of key users (i.e., those employees with good understanding of the university processes) early in the implementation is a useful tactic.

Involvement: Another factor that influences the uptake of an ERP system is level of involvement. Barki and Hartwick (1994) make a distinction between participation and involvement, stressing that the latter is psychological in nature. Involvement demonstrates the significance and individual relevance of the ERP system to the employees who use it. Both executive support and university management flexibility have shown to enhance ERP system user involvement (Ha and Ahn 2013; Ahmad, Ibrahim and Garba 2015; Galy and Sauceda 2014; Zhang, Gao and Ge 2013). The influence that these factors have on users is by way of affecting their motivation and morale, and this support is relevant even after the system go-live.

Attitudes: The attitudes of employees who use the ERP system have shown to affect two aspects of their behaviour: (a) intention to use the system to its full capabilities; and (b) intention to seek assistance (Barki and Hartwick 1994). Attitude is a feeling held by the employee, and if he/she feels negative towards the ERP system, his/her use will drop. Positive attitudes encourage greater usage. Low level of participation in ERP activities and developments results in negative attitudes (De Waal and Batenburg 2014). To build positive attitudes, Nwankpa (2015) recommends the provision of technical support and resources to users, whereas Esteves (2014) recommends training. In contrast, Schniedejans and Yadav (2013) recommend the building of user trust especially trust between users and university administration, and user's trust in the system itself.

Satisfaction with the system: Past studies have shown further that perceived usefulness of a technology as well as its perceived ease of use both influence usage (Kwak et al. 2012). Nwankpa and Roumani (2014) found evidence that satisfaction with an ERP system increases when its user is able to see that the system makes him/her perform better or if the system demands no additional reduced effort. In other words, the user must see how he/she can benefit from the system, and in that way, he/she will adopt it and use it. Weli (2014) suggests that user satisfaction with ERP system can be enhanced through improving the quality of the system, i.e., its reliability, accuracy, and its ease of use. Ali and Younes (2013) observe that informational quality, i.e., completeness of data, timeliness of information flow, and its accessibility heightens the usage of the system. The quality of training and support, particularly system support and 
information transparency, have a bearing on use because they improve user's level of satisfaction (Tsai et al. 2012).

\section{Reported motives for using ERP system}

Although some scholars have indicated that the readiness of the university as an enterprise for the ERP system is an important factor in its successful implementation (Bano and Zowghi 2015; Cavaye 1995; De Waal and Batenburg 2014), many others have maintained that users' motives for wanting to use the system, and their readiness for the technology (i.e., change management, capacity for learning, quality of training, and knowledge sharing mechanisms) are of even greater significance (Kwak et al. 2012; Sadki et al. 2015). When employees are ready for an ERP system by being properly trained and psychologically prepared, Ram, Corkindale and $\mathrm{Wu}$ (2015) argued that the benefits of the system to them, and the motives they construct for using it, are much clear and these include reciprocal interactions of cultural and social elements within the organisation. For example, the literature supports the view that the introduction of ERP system changes the manner in which the university operates and this intervention further changes its culture as an organisation (Pishdad and Haider 2013). In a university which is beset by internal conflict and confrontations, users of ERP system are likely to be motivated by the change since it streamlines workflow and minimizes person-to-person engagement (Tambovceva and Tambovceva 2013).

Current research also shows that when employees use an ERP system it is because they want greater convenience and satisfaction (Rose 2011; De Waal and Batenburg 2014). Kwak et al. (2012) argue that technology at work automatically conveys a sense of useful and ease of use which psychologically motivates employees/users. In other words, technology gives employees a sense that there is more convenience to experience in their work once it is adopted. Thus, in Kwak et al.'s (2012) analysis, the ERP system, and its novelty, inherently drives curiosity and may be a motivating force for some users to want to use the technology. However, these scholars warn that resistance to using ERP emerges when the expectations that its users hold fail to converge to the reality of the system.

The supreme motive driving employees to use ERP system seems to be the outcome that the system improves their job performance without them having to make any additional effort, or better yet at a reduced effort (Kwak et al. 2012). Scholars such as Verdouw et al. (2015) made the point clear by stressing employees' alleged benefits of the technology are the most significant motivator of ERP adoption and utilization. This implies that aligning the ERP technology with the job characteristics and necessities is the key source of motive to use the system. 


\section{Constraints reported in using ERP system}

Noaman and Ahmed (2015) reported constraints linked to the following factors but they did not elaborate in detail: unrealistic expectations from top management concerning the ERP system; too tight project schedule; poor top management support; poor quality of testing; poor quality of business process reengineering; poor knowledge transfer; poor it infrastructure; poor project management effectiveness; high turnover rate of project team members; and over-reliance on heavy customization; poor consultant effectiveness. However, Barki and Hartwick (1994) stressed that the most influential constraints on ERP uptake come from lack of user preparation, their lack of participation, involvement, negative attitudes, and dissatisfaction with the system.

In Botswana, there is still a dearth of higher education institutions with ERP system as a tool for resources planning and management. Although new requirements related to quality management from the local higher education regulator, i.e., the Botswana Qualification Authority, may motivate a greater push to install the technology, the limited roll out meant that published literature and direct experiences on the post "go-live" period in the country is scanty. Exploring this experience among internal stakeholders who use the system locally offer a critical bridge in this aspect of ERP.

\section{METHODOLOGY}

This research used a single-site case study design, in which both quantitative and qualitative methods were applied to offer a holistic picture (Yin 2014) of how internal stakeholders at the university (i.e. academics, students, and administrators) experience the use of ERP in higher education administration and management. One round of survey data collection as well as four (4) in-depth interviews were conducted. The mixed methods case study design suited this investigation as it strengthened the internal validity of the inquiry, while allowing the researchers to explore various experiences, feelings, and perceptions related to the usage of the ERP system (Creswell 2012; Yin 2014). These feelings and perceptions are reflected in the data gathered and analyzed.

Sample: A key step in designing the study was in deciding on the sample (O'Reilly and Parker 2012). Internal stakeholders comprising academics, students, and administrative staff in a public, large-sized flagship university in the African State of Botswana made up the sample. The rationale for selecting the flagship university in Botswana is that the university completed implementing its ERP system in March 2015, and had the following in place (a) Oracle EBusiness suite, and (b) PeopleSoft ERP. It is the only university in the country with a full ERP system, comprising of three module combination: finance, HR, and student record 
administration. In 2015, the university comprised of a student population of just over 15,000 fulltime and 2,000 part time, and a staff establishment of 940 academic and 1700 administrative staff. A purposive sample of 162 internal stakeholders - i.e., 97 students, 27 academics, and 38 administrative staff - were investigated about their ERP tool usage and experiences at the university. We focused on participants with direct experiences interacting with the ERP system because they stood the best chance to give accurate descriptions of their encounters. The sample demographics are shown in Table 1.

Table 1: Profile of sample

\begin{tabular}{|l|l|c|c|}
\hline \multicolumn{1}{|c|}{ Participants } & \multicolumn{1}{|c|}{ Descriptions } & Frequency & \% \\
\hline \multirow{2}{*}{$\begin{array}{l}\text { Academic staff } \\
(n=27)\end{array}$} & Male & 13 & 48.1 \\
\cline { 2 - 4 } & Female & 14 & 51.9 \\
\hline \multirow{2}{*}{$\begin{array}{l}\text { Administrative staff }(n=38) \\
\text { Students ( }=97)\end{array}$} & Male & 23 & 60.5 \\
\cline { 2 - 4 } & Female & 15 & 39.5 \\
\hline & Male & 47 & 48.5 \\
\cline { 2 - 4 } & Female & 50 & 51.5 \\
\cline { 2 - 4 } & $1^{\text {st }}$ Year - Freshers & 22 & 22.7 \\
\cline { 2 - 4 } & $2^{\text {nd }}$ Year - Sophomores & 23 & 23.7 \\
\cline { 2 - 4 } & $3^{\text {rd }}$ Year - Juniors & 27 & 27.8 \\
\cline { 2 - 4 } & $4^{\text {th }}$ Year - Seniors & 25 & 25.8 \\
\hline
\end{tabular}

Students were taken from across different year of study, and the number of male $(n=47)$ and female ( $n=50)$ students were approximately equal. This minimized biases towards particular gender in the responses. The administrative staff included members of the university's executive management, and ERP support staff who supply both degree and non-degree related services. However, the academic staff included faculty deans and academics that used the system online for personal as well as academic and student records administration. While the issues that affect internal stakeholders' experiences are likely diverse, we felt that the sample was diverse enough to capture these concerns across the strata of the university (Creswell 2012). The sample described themselves as computer literate, though some were more advanced in their literacy than others.

Data collection: The study was check for research ethics compliance by the researchers' Higher Degrees Committee. Data was collected with two methods; first, through questionnaires which were descriptive surveys with two sections; one section that included variables such as gender, year of study at university, computer literacy level, as well as questions exploring the frequency of computer usage, among other questions. The second section included variables on ERP functionality, the behavioural requirements of ERP system, ERP challenges, and questions regarding many of the tools detailed by Noaman and Ahmed (2015) in their discussion of the utilization of ERP modules in higher education administration, such as student records 
administration in Oracle PeopleSoft, procurement, among many others. These functionalities also appeared in past research on ERP in education (see, King et al. 2002; Swartz and Orgill 2012; Ndungu and Kyalo 2015). We also referenced Swartz and Orgill (2012) to measure experiences and encounters with ERP system tools.

In addition to the questionnaire, a follow-up in-depth personal interview also provided data for the inquiry. The interviews offered more depth into the internal stakeholders' lived experiences and the motives that drive them to use the system and how it can be improved. We asked "grand-tour” questions (Boeije 2002; Creswell 2012; Teddlie and Yu 2007) regarding the institutional ERP practices and challenges experienced during the interviews with four (4) internal stakeholders, namely: a student representative, academic representative, and two administrative staff representatives. We followed the interview protocol proposed by McCracken (1988). These interviewees were probed as to their experiences with the system overall and/or with specific modules, their key challenges, and how the system might be enhanced. Each interview lasted approximately 50 minutes, and it yielded textual data. The data from both the questionnaire and the interviews were analyzed.

Data analysis: The numeric and text data generated were analyzed differently. Following a process of pilot testing of the questionnaire on internal stakeholders at the university, the instrument was administered, and the SPSS software was used to generate frequencies and descriptive statistics. Both mean and standard deviations were the main statistics used. The two researchers further independently employed thematic coding in the analysis of the text data generated during the interviews. Following our convergence on salient themes, we integrated the verbatim with the numeric data in order to elaborate the various experiences (Boeije 2002; Creswell 2012; Teddlie and Yu 2007). In the qualitative data, strict measures of credibility applied were using fellow coauthor as critical friend of the data and the article overall, and combining methods. The findings are discussed in the sections below.

\section{DISCUSSION OF THE FINDINGS}

\section{Internal stakeholders' experiences ERP functionalities: Knowledge and usage}

Internal stakeholders' experiences with the ERP system implemented at the university were explored by asking the participants to report their familiarity with (a) PeopleSoft student records administration module, (b) human resources management module, and (c) financials module. Each of the ERP modules was measured using a 5-point Likert Scale, where 1 represents no familiarity and 5 represents high familiarity. Familiarity with the system depended on the user group and the module being referenced. As expected, administrative staff were highly familiar with all three modules: PeopleSoft student records administration module 
$(\bar{x}=4.33$, standard deviation $[S D]=0.704)$, human resources management module $(\bar{x}=4.51$, $S D=0.514)$, and (c) financials module $(\bar{x}=4.06, S D=0.701)$. The academic staff in contrast were highly familiar with the PeopleSoft student records administration module $(\bar{x}=4.88, S D$ $=0.521)$, but were less familiar with the human resources management module $(\bar{x}=2.31, S D=$ $0.414)$. They reported only some understanding of the financials module $(\bar{x}=2.50, S D=1.039)$ (see Table 2).

However, students reported that they were highly familiar with the PeopleSoft student records administration module $(\bar{x}=4.46, S D=0.621)$, but they had the least amount of understanding of the human resources management module $(\bar{x}=2.01, S D=1.312)$ and they lack understanding of the financials module $(\bar{x}=1.91, S D=0.701)$ (see Table 2). This was anticipated because the ERP functionalities such as the financials and human resources modules are outside students' access domain. The student records module is used to handle academic aspects that impact on student daily lives such as enrollment, class scheduling, academic calendar, course credits transfer, assignment submission, checking of course marks, and academic transcript. Understanding the ERP module which they used as they progress through the university is in their interest as students. Thus, stakeholders' experiences with the ERP system was consistent with the manner that the widespread notion anticipated. Familiarity with its functionalities depended on its user-groups.

Interestingly, the human resources and the financials ERP functionalities, respectively, preceded the launching of the PeopleSoft student record management module, but the administrative and academic staff indicated a high level of understanding of it in the same way that they understood the other modules, despite the shorter time in operation. One likely reason could be that the administrative and academic staff were forced by circumstances to understand these subsystems because the university was transforming and had as its agenda to improve services and the operations of the institution. The three modules installed (i.e., financials, HR, and student administration) are essential functionalities for transforming and improving university operations.

Table 2: Familiarity with ERP functionalities by internal stakeholders

\begin{tabular}{|c|c|c|c|}
\hline \multicolumn{1}{|c|}{ ERP functionalities } & $\boldsymbol{n}$ & $\overline{\boldsymbol{x}}$ & SD \\
\hline Academic staff & & & \\
\hline PeopleSoft student records module & 27 & 4.88 & 0.521 \\
\hline Human resources management module & 27 & 2.31 & 0.414 \\
\hline Financials module & 27 & 2.50 & 1.039 \\
\hline Administrative staff & & & \\
\hline PeopleSoft student records module & 38 & 4.33 & 0.704 \\
\hline Human resources management module & 38 & 4.51 & 0.514 \\
\hline Financials module & 38 & 4.06 & 0.701 \\
\hline
\end{tabular}




\begin{tabular}{|c|c|c|c|}
\hline \multicolumn{1}{|c|}{ ERP functionalities } & $\boldsymbol{n}$ & $\overline{\boldsymbol{x}}$ & SD \\
\hline Students & & & \\
\hline PeopleSoft student records module & 97 & 4.46 & 0.621 \\
\hline Human resources management module & 97 & 2.01 & 1.312 \\
\hline Financials module & 97 & 1.91 & 0.701 \\
\hline
\end{tabular}

The findings also indicate that although academics as internal stakeholders did not report full understanding of the ERP financials module, the data suggest that there is willingness to use various elements of that module. Concerning familiarity with elements such as inventory management, and daily business intelligence, nearly 88 per cent $(n=24)$ of academics reported good understanding of these submodules. Furthermore, their inventory management usage was maintained quarterly $(92 \%, n=25)$ for most and monthly for others. But academics agreed they did not understand most of the submodules within the financials module of the ERP system. Lack of familiarity of the financials module is indicated with only 16 per cent overall reporting some understanding of the tool (see Table 3).

While academics did not also use the HR modules in the ERP system, they were among the main users of the PeopleSoft module. Daily use of the enrollment submodule was reported by 96 per cent $(n=26)$ of the academics. Whereas all the academics $(100 \%, n=27)$ used the learning management submodule every day, only a few $(14 \%, n=4)$ used the student alumni and financing submodules, respectively, and the use was occasional. Campus analytics also showed common usage, but this was quarterly $(100 \%, n=27)$. In sum, academics reported the most usage of the PeopleSoft student records administration functionality, with the other functionalities such as the HR and the financials modules being less used (see Table 3).

Table 3: Academic staff's understanding and use of ERP modules

\begin{tabular}{|c|c|c|c|c|c|c|}
\hline \multirow{3}{*}{ ERP functionalities } & \multicolumn{6}{|c|}{ Academic staff $(n=27)$} \\
\hline & \multicolumn{3}{|c|}{ Understanding } & \multicolumn{3}{|c|}{ Use } \\
\hline & Responses & $\%$ & $\%$ Of cases & Responses & $\%$ & $\%$ Of cases \\
\hline \multicolumn{7}{|l|}{ PeopleSoft module } \\
\hline Enrollment* & 27 & 20.0 & 100.0 & 26 & 29.5 & 96.3 \\
\hline Alumni*** & 27 & 20.0 & 100.0 & 4 & 4.5 & 14.8 \\
\hline Student financing ${ }^{\star \star \star}$ & 27 & 20.0 & 100.0 & 4 & 4.5 & 14.8 \\
\hline Learning management* & 27 & 20.0 & 100.0 & 27 & 30.7 & 100.0 \\
\hline Campus Analytics** & 27 & 20.0 & 100.0 & 27 & 30.7 & 100.0 \\
\hline Total responses & 135 & 100.0 & 500.0 & 88 & 100.0 & 325.9 \\
\hline \multicolumn{7}{|l|}{ HR module } \\
\hline $\mathrm{HR}^{\dagger}$ & 2 & 6.7 & 7.4 & 0 & 0.0 & 0.0 \\
\hline i. Recruitment $^{\dagger}$ & 1 & 3.3 & 3.7 & 0 & 0.0 & 0.0 \\
\hline $\mathrm{HR}^{\text {intelligence }}{ }^{\dagger}$ & 1 & 3.3 & 3.7 & 0 & 0.0 & 0.0 \\
\hline
\end{tabular}




\begin{tabular}{|c|c|c|c|c|c|c|}
\hline \multirow{3}{*}{ ERP functionalities } & \multicolumn{6}{|c|}{ Academic staff $(n=27)$} \\
\hline & \multicolumn{3}{|c|}{ Understanding } & \multicolumn{3}{|c|}{ Use } \\
\hline & Responses & $\%$ & $\%$ Of cases & Responses & $\%$ & $\%$ Of cases \\
\hline Incentive compensation $^{\dagger}$ & 1 & 3.3 & 3.7 & 0 & 0.0 & 0.0 \\
\hline Payroll $^{\dagger}$ & 2 & 6.7 & 7.4 & 0 & 0.0 & 0.0 \\
\hline Learning management ${ }^{\star \star \star}$ & 23 & 76.7 & 85.2 & 1 & 100.0 & 3.7 \\
\hline Total responses & 30 & 100.0 & 111.1 & 1 & 100.0 & 3.7 \\
\hline \multicolumn{7}{|l|}{ PeopleSoft module } \\
\hline 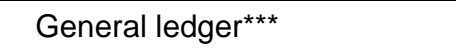 & 2 & 3.6 & 7.4 & 1 & 2.1 & 3.7 \\
\hline Accounts receivable & 2 & 3.6 & 7.4 & 1 & 2.1 & 3.7 \\
\hline Accounts payable & 2 & 3.6 & 7.4 & 1 & 2.1 & 3.7 \\
\hline Fixed assets ${ }^{\star \star \star}$ & 3 & 5.4 & 11.1 & 5 & 10.6 & 18.5 \\
\hline Inventory management ${ }^{\star \star}$ & 24 & 42.9 & 88.9 & 25 & 53.2 & 92.6 \\
\hline Daily Business intelligence ${ }^{\star \star \star}$ & 23 & 41.1 & 85.2 & 14 & 29.8 & 51.9 \\
\hline Total responses & 56 & 100.0 & 207.4 & 47 & 100.0 & 174.1 \\
\hline
\end{tabular}

On the other hand, while nearly 83 per cent of students $(n=97)$ reported good understanding of the PeopleSoft student records administration module, slightly lesser number on average (85\%, $n=97$ ) use the module content weekly. The most commonly used submodule in the PeopleSoft student records administration functionality was learning management, which was used weekly $(100 \%, n=97)$. This may be a result of the semester based modularized structure of the academic calendar at the university, because the learning management submodule gives students access to the course resources, and allow them to monitor their academic performance in terms of marks. The financing, alumni, and campus analytics submodules were used, but this was occasionally. Only few students however occasionally used the alumni $(19 \%, n=19)$ and the campus analytics (42\%, $n=41)$ submodules. In sum, students reported a relatively good understanding of the PeopleSoft ERP student records module. But they used some aspects of it more than others. They had no knowledge of the HR and financials functionalities in the ERP system.

Table 4: Students' understanding and use of ERP modules

\begin{tabular}{|c|c|c|c|c|c|c|}
\hline \multirow{3}{*}{ ERP functionalities } & \multicolumn{6}{|c|}{ Students $(n=97)$} \\
\hline & \multicolumn{3}{|c|}{ Understanding } & \multicolumn{3}{|c|}{ Use } \\
\hline & Responses & $\%$ & $\%$ Of cases & Responses & $\%$ & $\%$ Of cases \\
\hline \multicolumn{7}{|l|}{ PeopleSoft module } \\
\hline Enrollment* & 97 & 20.4 & 100.0 & 97 & 27.6 & 100.0 \\
\hline Alumni ${ }^{\star \star \star}$ & 96 & 20.2 & 99.0 & 19 & 5.4 & 19.6 \\
\hline Student financing ${ }^{\star \star \star}$ & 97 & 20.4 & 100.0 & 97 & 27.6 & 100.0 \\
\hline Learning management* & 97 & 20.4 & 100.0 & 97 & 27.6 & 100.0 \\
\hline Campus Analytics** & 88 & 18.5 & 90.7 & 41 & 11.7 & 42.3 \\
\hline Total responses & 475 & 100.0 & 489.7 & 351 & 100.0 & 361.9 \\
\hline
\end{tabular}


With regard to the administrative staff, over 90 per cent $(n=38)$ indicated full understanding of all three of the ERP module functionalities. Unlike with other internal stakeholders, the majority of administrative staff (90\%) on average reported that they used the systems daily. All the administrative staff, who included the executive management and the support staff, used the different submodules in each of the three ERP functionalities, daily. However, the exception is that only few administrative staff used, daily: (a) the campus analytics in the PeopleSoft functionality (10\%, $n=4)$; (b) the HR intelligence (8\%, $n=3)$ and $i$.Recruitment $(13 \%, n=5)$ submodule in the HR functionality; and (c) the fixed assets $(21 \%, n=8)$ submodule in the financials functionality.

Taken as a whole, it is evident that despite the diverse group of administrative staff, there were few members of this group who used certain submodules in the ERP system less frequently than others.

Table 5: Administrative staff's understanding and use of ERP modules

\begin{tabular}{|c|c|c|c|c|c|c|}
\hline \multirow{3}{*}{ ERP functionalities } & \multicolumn{6}{|c|}{ Administrative staff $(n=38)$} \\
\hline & \multicolumn{3}{|c|}{ Understanding } & \multicolumn{3}{|c|}{ Use* } \\
\hline & Responses & $\%$ & $\%$ Of cases & Responses & $\%$ & $\%$ Of cases \\
\hline \multicolumn{7}{|l|}{ PeopleSoft module } \\
\hline Enrollment & 38 & 20.0 & 100.0 & 26 & 18.1 & 68.4 \\
\hline Alumni & 38 & 20.0 & 100.0 & 38 & 26.4 & 100.0 \\
\hline Student financing & 38 & 20.0 & 100.0 & 38 & 26.4 & 100.0 \\
\hline Learning management & 38 & 20.0 & 100.0 & 38 & 26.4 & 100.0 \\
\hline Campus Analytics & 38 & 20.0 & 100.0 & 4 & 2.8 & 10.5 \\
\hline Total responses & 190 & 100.0 & 500.0 & 144 & 100.0 & 378.9 \\
\hline \multicolumn{7}{|l|}{ HR module } \\
\hline $\mathrm{HR}$ & 38 & 19.7 & 100.0 & 38 & 23.8 & 100.0 \\
\hline i. Recruitment & 38 & 19.7 & 100.0 & 5 & 3.1 & 13.2 \\
\hline HR intelligence & 3 & 1.6 & 7.9 & 3 & 1.9 & 7.9 \\
\hline Incentive compensation & 38 & 19.7 & 100.0 & 38 & 23.8 & 100.0 \\
\hline Payroll & 38 & 19.7 & 100.0 & 38 & 23.8 & 100.0 \\
\hline Learning management & 38 & 19.7 & 100.0 & 38 & 23.8 & 100.0 \\
\hline Total responses & 193 & 100.0 & 507.9 & 160 & 100.0 & 421.1 \\
\hline \multicolumn{7}{|l|}{ Financials module } \\
\hline General ledger & 38 & 16.7 & 100.0 & 38 & 19.2 & 100.0 \\
\hline Accounts receivable & 38 & 16.7 & 100.0 & 38 & 19.2 & 100.0 \\
\hline Accounts payable & 38 & 16.7 & 100.0 & 38 & 19.2 & 100.0 \\
\hline Fixed assets & 38 & 16.7 & 100.0 & 8 & 4.0 & 21.1 \\
\hline Inventory management & 38 & 16.7 & 100.0 & 38 & 19.2 & 100.0 \\
\hline Daily Business intelligence & 38 & 16.7 & 100.0 & 38 & 19.2 & 100.0 \\
\hline Total responses & 228 & 100.0 & 600.0 & 198 & 100.0 & 521.1 \\
\hline
\end{tabular}




\title{
Possible motives for using ERP system for resources management in higher education
}

The university invested approximately P68 million (US\$6.4 million) to set up the ERP system. King, Kvavik, and Voloudakis (2002) developed a typology of motives for ERP system use that details three primary motivations: management efficiency; customer satisfaction; and information accuracy. Internal administrative staff expressed during in-depth interviews that they were generally satisfied with the ERP system overall, and gave reasons. They expressed that although there were hiccups in some areas, the system had contributed several benefits, among which were the reduction in paper forms, and the opening up of online accesses. Implicit in these reasons are the fact that the system has contributed to improve efficiency in management. One of the administrative managers explained:

\begin{abstract}
"There are two things the system has, as its immediate impact. We came from a lot of paper where processes were basically by a lot of paper moving around. But now many of our processes are automated. The self-service gives all the university staff the platform to request common services such as leave. And even when we talk about modules ... let's take the financials module, for example, it comes with processes like assets management which we used and it is helping. The feedback I get from people (university staff) is that everybody is happy.” (Manager 1).
\end{abstract}

In the experiences of the manager, the ERP system implemented improved service delivery. Service delivery enhancement is an essential outcome of management efficiency. Sentiments about management efficiency were shared and further endorsed by other managers. One noted, “... the biggest benefit for me is the acceptance of the system, and the management information reports we are now able to generate because we had management information infused into the budget cycle which gave everyone the chance to make informed decision ...” (Manager 2). Other managers highlighted the automation of, and convenience in, process experience: “... the good thing with the new system is automation ...” (Manager 3 ), and convenience, “... as for the first time, we had online registration of our students which meant lesser time cross-tabulating” (Chief Executive Officer). These anecdotes corroborate the pattern of responses that administrative staff gave in the survey. The responses inform us that, with the transition from the legacy management information system, the university stakeholders have been able to experience a gradual improvement in access to consolidated information for resource planning, as well as in the enhancement of workflow and process controls. In respect of King's et al. (2002) topology, these benefits are consistent with the management efficiency motive in typical ERP systems in higher education.

The administrative staff expressed positive sentiments about students' responses to the ERP system. A senior manager (Manager 4) responsible for handling the functional and 
technical aspects of the PeopleSoft student records administration component of the ERP system agreed that students have embraced the use of the module generally, and the idea of being able to engage with some processes such as registration and course resources at their own convenience. He described and attributed the reasons for this as an outcome of the dynamic partnership between the academic staff and students, “... they [students] embraced the system ... and the dynamics between [the] students and [the] academic staff, I think, played a big role in swinging the minds of any resistance that we had on the academic side”. The students' interest in, and acceptance of, their ERP module contributed to winning over skeptical academics who had minimal faith in the ERP system. Skeptical academics were challenged by students, as one explained:

"There were lecturers [academics] who used to say there were problems with the [PeopleSoft] system, but we knew that that could not be because we saw other faculties using it. That's when we said to them [academics], if there were problems with it [ERP system], why were other faculties not having the same kind of problems?” (Student representative).

Students were driven by a convenience motive for using the PeopleSoft student records administration component of the ERP system. And this motive was in a manner that was often intertwined with an information motive. King et al. (2002) outline that convenience motive as students being able to get updated course resources without necessarily being physically present in lectures; finding out about registration, academic progression, lesson schedules, campus activities, and coursework assignments with little effort or with no hindrances. The information motive - which includes seeking guidance, interacting with classmates, inquisitiveness, and finding out - mutually reinforces the convenience motive. The student representative interviewed talked about the convenience he felt with checking coursework for plagiarism through platforms like Turn-it-in and downloading course materials, “... the ERP platform is a way to keep us engaged ... there are many more things we now do on our own to prepare before the lesson; the lecturers upload the lecture materials ahead of the lesson and we are able to read and prepare for the lesson ... we can subject our course assignments to Turn-in-in ...”. Similarly, the student representative revealed how the PeopleSoft ERP module provides an outlet for “... staying current with developments in the course of study ...”. Thus, while the convenience motive goes together with the information motive, it provides evidence that, as customers, the students were generally satisfied with the new services that the ERP offered them.

However, the motives that students had for using the ERP system were different from those of the other internal stakeholders. Table 6 further summarizes the motives that administrative and academic staff expressed for using the ERP functionalities. 
Table 6: Why administrative and academic staff use the ERP system $(n=65)$

\begin{tabular}{|c|l|c|}
\hline No. & \multicolumn{1}{|c|}{ Reasons } & $\bar{x}$ \\
\hline 1 & Improved university processes & 2.99 \\
\hline 2 & Improvement in management information & 2.97 \\
\hline 3 & Improved access to management information & 2.95 \\
\hline 4 & Improved services to students, faculty, and staff & 2.92 \\
\hline 5 & New services added for students, faculty, and staff & 2.83 \\
\hline 6 & Institutional accountability & 2.40 \\
\hline
\end{tabular}

The most common reason that drove administrative and academic staff to use the ERP system is the sense that the university processes have improved $(\bar{x}=2.99)$, and that there is enhanced management information $(\bar{x}=2.97)$. Improved accessibility to information led to improvement in service delivery. These reasons, and others reflected in Table 6, substantiate earlier sentiments about system automation, convenience, management efficiency. Interestingly, however, the motives of information accuracy mentioned by King et al. (2002) did not emerge as prominent themes.

\section{Barriers and concerns in maximizing the use of ERP functionalities for university resources management}

We asked the internal stakeholders about the barriers and concerns they hold about the ERP system and utilizing it. Experienced and perceived barriers (extrinsic), as well as personal concerns that the internal stakeholders had, or anticipated, (intrinsic) were explored. The data reveals barriers that can roughly be categorised as (a) technical barriers, e.g., access to support and guidance; and (b) functional barriers, e.g., relapse into old habits; transitional change management deficiencies; management buy-in challenge; confidence of colleagues, self, and students.

Administrative and academic staff expressed that they did not believe the ERP technology was fully utilized. In their experience, approximately 70 to 80 per cent of the system is being used, and that had a higher percentage been used, the system would have added greater value. Administrative staff made the rough estimate, remarking, “... if you asked me, to what extent [am] using the system, I would say probably 70 to 80 per cent ... if today we are asked, how many professors do we have in the University, for example, we still have some of us who would do that [analysis] manually, i.e., counting with fingers, but the system can do that for us.” The inherent point is that the ERP system is not being used optimally. Barriers that internal stakeholders face contribute to the low optimization. 


\section{Relapse into old habits}

Administrative and academic staff see "relapse into old habits" as a significant barrier to maximizing the use of the ERP system, and gaps in the change management process to support full transition. Relapsing into old habits results after the system has been tried for a short time (e.g., few days or weeks), and then employees find themselves resorting, periodically or wholly, thereafter to using old methods of working. A senior HR manager (Manager 3) referenced relapse, by pointing to the reality that some employees resorted to "counting with fingers" when asked to provide certain statistics, which the ERP system could produce, on the university establishment register. In other words, these internal stakeholders opted to operate a parallel manual system. The introduction of the ERP technology for resource planning within the university environment meant that internal stakeholders have had to learn and accommodate new behaviours and ways of thinking. Transforming employee work habits to ensure a lasting behavioural change that accommodate the new behaviour is a process, which can be prolonged. Nevertheless, relapse is an indication that the new behaviour has not stuck. Thus, administrative and academic staff who, for example, opted to "count with fingers” had not sufficiently grooved in the habits to reflexively respond using the ERP technology.

“... if people are used to working in a certain way ... a [new] system usually involves changing the way people actually do their work ....” (Manager 1).

"We may have a system that operates in an integrated way but our staff do not think in an integrated way. They still think and operate in their own silos, though the system broke down silos." (Manager 2).

Mindset inflexibility buttresses the relapse. As brought out in the evidence above, "silos" metaphorized the mental frame that persisted and guided internal stakeholder behaviour in the ERP system post-launch period. "Silo" thinking suggests disaggregation and disintegration, which is antithesis to the basic principle of integration on which ERP functions. It appears the ERP technology is being underused because the mindset of its operators is out of harmony with the fundamental principle (mindset) of the system. The central point that Manager 2 has made is that although the ERP technology is an integrated-computerized-system, there were internal stakeholders who operated as though they were using fragmented systems, as they did in the past.

Several forces seem to drive the inflexible mindset that underpins the relapse. Prominent among these is the idea of being in a "comfort zone" with the old system. Administrative and academic staff comments emphasized this point: “... You always have people in their comfort zone with the old system, and building empires with the old system ... they see [the introduction of] the change to the new [ERP] system as eroding their power base ...”. The comfort zone 
represents a settled method of working, requiring limited effort but at the same time yielding almost a satisfactory result. It is a place where employees feel safe and at ease. The notion that administrative and academic staff falling back to their comfort zone provides clues that, rather than take on the new paradigm that the ERP system imposes, the staff instead took the easy way out by resorting to old familiar habits. Perhaps the reason for this, Manager 2 expressed, is to protect their sphere of influence and power base.

The evidence also highlights that although the administrative and academic staff expressed a fear of loss of influence as a result of the ERP system, their relapse was also a result of inactive self-management. Active self-management manifests in self-directed activities, including ongoing reflexivity to determine what contribute to the relapse, the formulation of replacement habits, and self-monitoring to detect deviation or relapse. Using the ERP system without ongoing reflection and self-monitoring means that the chance to rapidly notice when one gets off track from the new routine associated with utilizing the system fully, diminishes. Some administrative and academic staff acknowledged low self-management as source for relapse in behaviour:

\footnotetext{
"Continuity in training people is needed ... Nobody track their own habits as they use the [ERP] module in their function, so when they fall back into their old habits such as wanting to do things manually, or work as if the system was disjointed, it becomes difficult for them to tell what causes the relapse. Personally, I don’t keep track of myself at all.” (Manager 2).

“... It is mainly the attitude ... it is mainly the perception ... that is barring people from seeing or [fully] appreciating the capabilities of the [ERP] system ... when people doubt if the system can do what it claims, then it leads to old habits accommodation ....” (Manager 3).
}

Although the internal stakeholders use the ERP technology, they held negative perceptions and doubts about its capabilities. But these sentiments are unhealthy as they buttress relapse, and feed into feelings of reluctance among these employees to go the extra mile to self-manage their habits so as to detect relapse tendencies, or to move out of their comfort zones and "silos" in order to maximize the use of the ERP system.

\section{Transitional change management deficiencies}

The evidence on barriers revealed that the underuse of the ERP functionalities for university resources planning resulted from weaknesses in the change management arrangements. While the university invested in the technology, the data shows that the university administration misjudged the scope of the change management requirements, as they assumed that the continuation of change management activities after the launch, or the "go-live", of the ERP system was unnecessary. This decision proved disastrous. Many of the problems that 
administrative and academic staff attributed to the underuse of the system were linked to the absence of any formal ERP post launch change management plan. One HR manager spoke about the absence of debriefing plans following the "go-live" period to return staff who worked as functional experts in the team back to their respective departments; while a senior manager in the finance division was saddened by the lack of continuity in change management, which the stakeholder blamed for much of the doubts that employees held about the capability of the ERP system. For example, HR manager explained:

"The ERP team had people drawn from different departments, based on their functional expertise ... there were people from HR, Accounts, procurement, registry, student representative, and so on ... we worked with them as team for over a year, and after the launch, nobody tries to transition them back to their normal units, or facilitates the transfer of the knowledge they gained about the ERP system to other staff in their respective department.” (Manager 3).

In a similar vein, the finance manager lamented his sadness about the lack of continuity in managing the change after people begun to use the system:

“Change is an everyday thing ... It's not a once off thing. We can't talk only of change that happened at the migration stage, or at any other time, and then think, ok ... everything has been taken care of. We ignore the changes, and reactions from people, after the system has been handed over to us to use it ... and that is why the usage to me is not as I would have liked it." (Manager 2).

A senior academic, who worked for many years without the integrated ERP, expressed indifference about not anticipating and managing ERP post launch or "go-live” changes:

"We knew people would change how they work, once the system was up and running, but we did not try to ease them into it and continue to support them, through training and counselling, and so on. These turned people off from committing to the system.” (Manager 1).

What appears evident from the above extracts is that there are two groups of ERP users as a result of how the transitional change management was handled. There are those users who were part of the ERP functional team and who participated in the system development, and consequently who fully understood and appreciated the system. On the other hand, there are those who were not part of the system's development, and consequently had limited skills transferred to them. The latter seem to be the group that held doubts about the capabilities of the system, and are making its usage not what it is supposed to be. The knowledge gap between the group members fueled strained relationships, division and conflict. The HR manager admitted, “... there was a split that existed between staff members who were in the ERP 
development and those not in it, and the riff continued into the 'go-live' phase ...”.

Administrative and academic staff from both groups however expressed mostly negative views of the absence of post launch change management undertakings, perceiving it as a major factor in the underuse of, and reactions to, the ERP system, and describing the deficiency as exuding the evidence of weak support from the university administration for developing internal users. In other words, the perception is that while the university administration invested heavily, in financial terms, in the technology and its related hardware requirements for it to be installed, they did not invest as much effort in the "soft support" to ease employee transition into, maximizing the use of, the system.

\section{Detached persona of the university administration}

The detached persona of the university administration was also viewed as further barrier contributing to the transitional change management challenges. One manager cited lack of management appreciation, noting: “... the university never really showed appreciation of the [functional/technical] team ...” and the dismissive attitudes towards suggestions: “... we recommended having an office responsible for ERP uptake and usage but it seems not to have made sense to the authorities ...” as setbacks in the continuation of change management activities following the "go live" phase. In this kind of interaction, communication is stifled, yet it is essential, as it is through communication that the "word" gets out particularly between the university administration and the project team, and between the university administration and users, to ensure clarity of plans in the ERP post launch phase. However, the initial seed of indifference towards the "soft support" for ERP users, sown by the university administration appears to have left some level of negativity towards the system. As a result, some internal stakeholders seem influenced by the behaviour and relied on parallel manual systems and paperbased processes. But when the persona of top management does not align with, and feed into, the plans on the use of the technology, the chance of obtaining employees' full commitment is weak. The detached persona is a barrier that triggers ripple effects.

\section{Inadequate training, support and guidance}

Academic and administrative staff agreed that inadequate training and guidance were among their most significant barriers, with both groups acknowledging that these weaknesses played a role in preventing the full utilization of the ERP system. Internal stakeholders spoke at length about the absence of formal training in the post launch period, and the unsatisfactory support they receive from the internal technical team. However, as the evidence indicate above, the absence of appropriate and deliberate post launch change management arrangement meant that the technical team did not transition back properly to their departments. As Manager 3 
explained above, this meant that the knowledge which the team members gained in the development of the ERP system was not necessarily transferred to other staff with whom they work. Inappropriate transitioning of these experts, along with no suitable structure that facilitate the sharing of their knowledge, can also add to the myriad of reasons why academic and administrative staff felt the support they received from the technical team was unsatisfactory.

Whereas inadequate preparation manifested in practices such as the absence of dedicated training resources, discontinuity in training to end-users, and poor scheduling of training, inadequate support, on the other hand, was revealed also in slow response from internal IT personnel to request for technical assistance. More crucially, though, is that the absence of ongoing training was worrisome for academic and administrative staff as they reasoned that it implied (a) there were no new staff joining the university, and that (b) at the initial end user training, everybody learnt everything that's needed for the full use of the ERP system. They maintained both assumptions were misleading, and suggested that the risk of not training people properly on the use of the ERP system is that the cost invested in setting up the technology will eventually go in vain.

"Continuity in training people is needed. [This includes] continuingly training even the trainers who train us because the trainers also need to have their knowledge/skills updated so that we are all kept relevant... but now, there is no training for us, even for those trainers, as if we are saying there are no new people joining, or that at the time of training, everybody got everything right”. (Manager 3).

“... The level of support is not satisfactory ... our IT team is trying hard but the biggest problem is that this is a platform that they are not familiar with ... the situation is made worst by external consultants who have questionable technical abilities.” (Manager 1).

What appears clear from the above verbatim is that owing to the weaknesses in the ERP training and related support, internal stakeholders who use the different ERP technology modules have had to discover how to maneuver the system on their own.

\section{Concerns}

All groups were asked about their concerns with regards to the use of the ERP system. Questions were asked in relation to their personal concerns about the system, including information and system quality, service quality, system efficiency and operational efficiency and effectiveness. Overall, the internal stakeholders were least concerned about the operational efficiency and effectiveness of the ERP system because these were variously demonstrated in provisions such as service notifications, automated workflow, service integration, enhanced information, online self-services, as well as in user productivity, error reduction, and improved 
audit and management controls. The stakeholders within the university were also least concerned about the basic knowledge and skills of themselves, and the students using the system.

However, they were and more concerned, particularly academic and administrative staff, about information quality - specifically, its accuracy, and up datedness. They were concerned too about service quality issues such as training, and the service responsiveness and competence of the ERP support team. The data further shows that, while external consultants were generally seen as helpful, internal stakeholders were concerned about their rapid turnover because with each new team, a period of familiarization ensued which the users had to do. The repetitive nature of the task strained the stakeholders. Figure 1 summarizes the issues that concerns were expressed about.

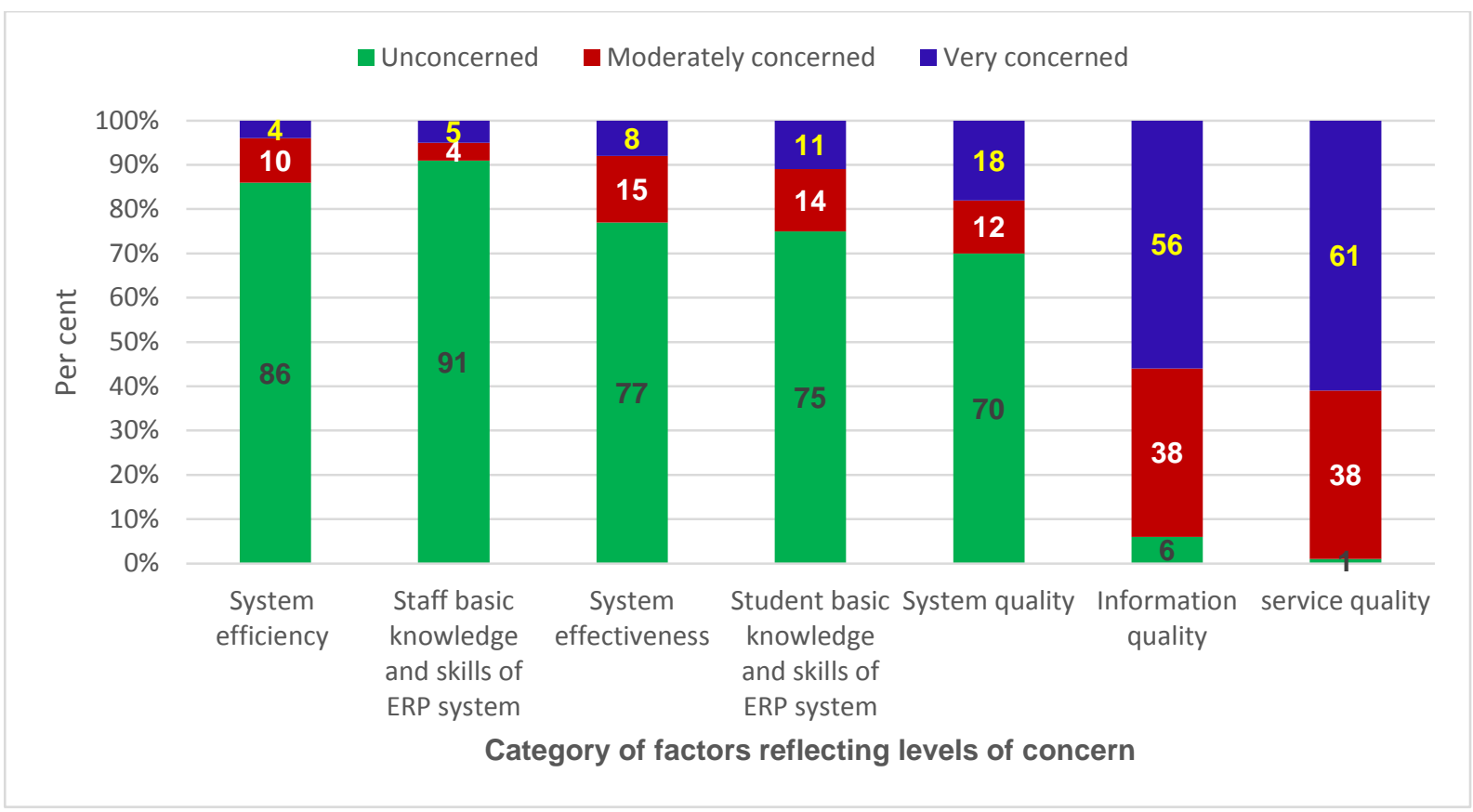

Figure 1: Internal stakeholders' concerns

\section{FURTHER DISCUSSION}

The study investigated three aspects of ERP usage in the immediate period (first 18-24 months) after the system was launched and mandated as the policy and tool for resource planning at the flagship university in Botswana, Africa. The three issues assessed were (a) internal stakeholders' familiarity and use of the ERP system. Internal stakeholders were academics, students, and administrators; (b) the possible motives for using the ERP system; and (c) the barriers encountered and concerns held as the system is utilized. In general, the stakeholders sampled were familiar with the ERP system installed, but use of the system varying, depending on the user group and the module in question. The stakeholders showed high familiarity with, 
and usage of, the module(s) that was tailored to their particular needs. Academics and students were highly familiar with and highly used the PeopleSoft student records administration module, but unlike the students, the academics were also familiar with and used elements of the HR module but not the financials module. In contrast, however, the administrative staff were familiar with and used all three modules in the ERP system largely because they worked in general university administration which had to plan resources across the enterprise. Current research suggests that with the emphasis on specialization of functions and segregation of roles, it is inevitable that no single person necessarily need to know everything about the operations of the organisation (Rueffler, Hermisson, and Wagner 2012). As such, these findings were in line with expectations.

The motivation for using the ERP system for resource planning in higher education revealed some surprises. While there can be a diverse set of motives for the use of an ERP system, the reasons that internal stakeholders shared were consistent with the three primary motivations of management efficiency; customer satisfaction; and information accuracy advanced by King, Kvavik, and Voloudakis (2002). The stakeholder used the ERP because it contributed to a reduction in paper forms, and the opening up of online accesses. The system improved service delivery for not just internal customers but also for those external. What appears clear from the evidence is that the underlining motivation was to achieve management efficiency, as King, Kvavik, and Voloudakis (2002) suggested.

Furthermore, a theme that was common across all the groups as a motive to use the ERP technology is convenience. Students were driven by a convenience motive as they could access online resources and services. The convenience for them was in a manner that was often intertwined with an information motive. However, for the administrative and academic staff, the convenience was in the sense that the university processes have improved. It is very interesting to note that internal customers cannot be taken for granted by any unscrupulous university administration in the new millennium because they are quite aware of the level of satisfaction they want as customers whether as employees or as students. This means that King, Kvavik, and Voloudakis's (2002) second motive of customer satisfaction was support by the data. Interestingly, however, the motives of information accuracy mentioned by King et al. (2002) did not emerge as prominent themes. To the contrary, information accuracy emerged as a major concern, rather than as a motive for using the system. In our study therefore, a factor that King et al. (2002) posited as a motivator emerged as a demotivator because unreliable and inaccurate information dim stakeholders' interest in the system (Swartz and Orgill 2012; Ndungu and Kyalo 2015).

But while the university can celebrate the management efficiency and customer satisfaction benefits that emerged from the system so far, Shanks, Seddon and Wilcocks (2003) 
cautioned that those merely reflect operational benefits, and that deeper and much more fundamental motives linked to strategic underpinnings must still be explored and understood. Shanks et al. (2003) suggest it can takes up to two years for organisations to come out of the familiarization stage of an information system, which perhaps give some indication as to why the motives have largely been on tactical level outcomes.

What appears clear from the findings above is that the university administration along with its internal stakeholders seem not to be aware of the tactics they could utilize in order to mitigate emerging barriers that prevent them from maximizing the use of the ERP functionalities for university resources management. Four fundamental barriers, along with concerns, were discovered, and these included users' relapse into old habits, deficiencies in transitional change management, a detached persona of the university administration, and inadequate training, support and guidance for the stakeholders, particularly those who were not part of the functional team that developed the ERP system. In the use of any technology, barriers are bad news, and it is more so the case with ERP systems because they minimize the benefits that the organisation can obtain from the massive financial investment (Swartz and Orgill 2012). The barriers reported in this study are forceful and strong as they contributed to division among some internal stakeholders, and based on Al-Mashari's (2003) warning - about the lack of continuing training - we can safely point out that the barriers reported have the potential to jeopardize the long term success of the ERP system.

Finally, research advocates for high level of support when promoting an uptake of new technology (Noaman and Ahmed 2015; Pollock and Cornford 2005). This is based on a strong link between support (formal or informal) and employee confidence, and their subsequent readiness and eagerness to try new things to maximize the use of the technology, such as in our case an ERP system. Our study found evidence of inadequate training, inadequate support and guidance, as well as concerns about information accuracy and up datedness. As the university rolls in the ERP system, it is clear that the institution is on pathway that is antithesis to what past research recommends.

\section{CONCLUSIONS AND WAY FORWARD: MITIGATING IDENTIFIED BARRIERS AND CONCERNS}

ERP system in a university is not the mere procuring of the application and installing it. The phase after the system "go-live”, and has been handed over to its users is a vital part of establishing the system. It represents a period that requires a considerable investment that matches the financial investment that went into procuring the technology and setting it up.

This study added to the body of knowledge regarding experiences of, and barriers to, maximize the usage of an ERP system. While it may be reasonable to conclude that the 
university's rationale for installing the system has been achieved - given evidence confirming enhancement in management efficiency and in customer satisfaction - there is a preponderance of reasons for the university administration to be worried. The phase after the system "go-live" has taken on a life of its own, characterized by not just the general underutilization of the ERP technology but also concerns about its information quality. These resulted from weak end user training, support and guidance. Underuse was also inspired by other forces, including relapse into old habits triggered perhaps by weak support base; deficiencies in transitional change management; and a detached persona of the university administration. With these obstacles, stakeholders' had limited support to build their confidence and a willingness to explore with new things to maximize the use of the technology.

Nevertheless, the internal stakeholders relished the convenience that the ERP brings, which means that all hope in the system is not loss. With deliberate effort to alleviate the reported barriers and concerns, the university administration could refocus itself onto a pathway where it can maximize the use of the ERP technology. The way forward is to put measures in place to mitigate the identified barriers and concerns. To overcome barriers and implement measures that will maximize the usage of the ERP system, we recommend the following:

Training throughout the post "go-live" phase: It is obvious that the university needs to do something about its user training. Inadequate ERP training is a weakness that the university faces. Training is key to how the internal stakeholders adapt and use the ERP system at their jobs. The university should (a) prioritize continuing ERP training throughout the go-live; (b) it should make training compulsory for internal stakeholders, and it should cover all aspects of ERP functionality and information and system quality. The training should be customized, i.e., based on stakeholders' needs, and should span from the top to the bottom of the university. This way, relevance is maintained, relapse into old habits reduced, human errors are minimized, and information quality improved. Training should take different modes of delivery. This way, internal stakeholders can accommodate the training within their schedules. Targeted training should be offered throughout the year to various internal user groups: academics, administrative staff, and students.

Provide timely ERP support throughout the post "go-live” phase: Recruit the talent needed to provide the best ERP support, and retain them. Timely support minimizes the ERP system to grind to a halt, and minimizes relapse into old habits. Focus support on critical areas. Three examples from this inquiry include: system reliability, system response time, and ease of use of the system. Information quality and service quality must be prioritized for support. A thorough analysis of the type of reports stakeholders need should also be prioritized and should be ongoing. Data and system validation minimize risk and contribute to confidence building in the system; a dedicated resource to undertake this task can assist the change management and 
problem tracking process for the system at the university.

Social change: As we have observed in this study, stakeholders who participated in the development of the ERP system showed subsequently higher levels of familiarity, involvement, attitude, and system usage. User participation theory affirmed this outcome (Barki and Hartwick 1994). The other set of academic and administrative staff that were not involved in that development process should be taken through a knowledge transfer scheme, supported and facilitated by those team members who helped develop the system. While the experience may not necessarily be the same, the knowledge transfer could contribute to positive change between the groups. Beyond the above, harmonization in the outlooks that the groups hold of each other raises the potential for a maximization of benefits from the ERP system. This means, the university administration and its stakeholders can direct their resources for positive social change outside the university, e.g., community services. The critical lesson that the university should learn nevertheless is that the inclusion of all users early in the development of the change is important.

"Go-live" change management plans: We have learnt through this inquiry that the university had no formal change management plans in place subsequent to the phases and overall ERP system "going-live”. The formal plans can still be implemented, though delayed. The change management plans should focus on critical issues, e.g., social change, training, ERP support, and problem tracking. It should also deal with consultant engagement issues, internal stakeholder preparation, attitudes, and so on. The change management scheme should address the detached persona of the university administration, and support the administration to take full responsibility for the success of the ERP system, without passing that responsibility off to outside consultants and expect at the same time that its internal stakeholders will adopt the system.

The university administration can begin to demonstrate deep commitment for the system by taking practical steps: (a) forbid the use of parallel manual systems; (b) insist on the full use of all ERP modules; (c) become advocate for the system and share its success stories; and (d) insist on new staff induction and have process in place for such induction.

\section{IMPLICATIONS FOR HIGHER EDUCATION}

It is evident that employing strategies to maximize the use of ERP can provide higher education institutions with enhanced productivity through integration, standardization, and simplification of its processes. Higher education managers and those leaders responsible for technology such as ERP system adoptation need a clear appreciation and understanding of ways to take full advantage of the use of their ERP systems. One of the key messages from this investigation for higher education broadly is that, as higher education managers invest in ERP systems, and take 
steps to convince its internal stakeholders to use the system, the university benefits from the system only to the extent that its internal stakeholders accept the system. It is only then, after full acceptance is achieved, that the full capabilities of the system can be optimized. Higher education institutions in Africa, in particular, should invest in more than the technology; they must also invest in the preparation and development of the people to use the system, particularly in the period after deploying the technology.

A second lesson for higher education is that the users of the system cannot be left behind while the thorny issue of getting the functional and technical requirements of the system right. Internal stakeholder involvement and more particularly, participation, from the very early stages of developing the ERP system is the key stage to roll out strategies to get these stakeholders to optimize the use of the system. The effective of this early preparation too is that it creates a common baseline for everyone, cultivate ownership, and minimizes the chance of conflict, tensions, and division because it nullifies a situation whereby some stakeholders participate and understand the system and others do not.

In addition, higher education can learn from this study that the upper echelon of the university administration cannot treat the process transformation as an appendage to be dealt with by others. Their leadership is necessary throughout the entire process, from initial conceptualisation through to and throughout the post go-live period. Higher education executives must lead the change management process, and this process should span into at least the first two years after go-live, to ensure full transformation and system maximization. The presence of the higher education executives motivates, inspires a positive environment for maximizing system capabilities, and places them in a position to connect with the lived reality of users.

\section{ACKNOWLEDGEMENTS}

Our gratitude goes to all the students, academic and administrative staff for taking the time to participate.

\section{REFERENCES}

Ahmad, S., S. Ibrahim and S. Garba. 2015. Enterprise resource planning (ERP) systems in banking industry: Implementation approaches, reasons for failures and how to avoid them. Journal of Computer Sciences and Applications 3: 29-32.

Ali. B. and B. Younes. 2013. The impact of ERP system on user performance. Journal of Theoretical and Applied Information Technology 52: 325-342.

Al-Mashari, M. 2003. A process change model for ERP implementation. International Journal for Human Computer Interaction 16(1): 39-55.

Althonayan, M. 2013. Evaluating stakeholder performance of ERP systems in Saudi Arabia Higher Education. Doctoral thesis. Department of Information System and Computing. Breuni University. 
http://passthrough.fw-notify.net/download/349015/http://dspace.brunel.ac.uk/bitstream/2438/ 7502/3/FulltextThesis.pdf (Accessed 10 March 2017).

Bano, M. and D. Zowghi. 2015. A systematic review on the relationship between user involvement and system success. Information and Software Technology 58: 148-169.

Barki, H. and J. Hartwick. 1994. Measuring user participation, user involvement, and user attitude. MIS Quarterly 18: 59-82.

Boeije, H. 2002. A purposeful approach to the constant comparative method in the analysis of qualitative interviews. Quality and Quantity 36(4): 391-409.

Cavaye, A. 1995. User participation in system development revisited. Information \& Management 28: 311-323.

Charisma. 2014. Charisma solutions. White paper. http://www.charisma.ro/en/erpsolutions/clients/ expertise/resources/analysis-and-case-studies/behind-the-scenes/erp-for-the-leasingindustry/ (Accessed 10 March 2017).

Chou, H., Y. Lin, H. Lu, H. Chang and S. Chou. 2014. Knowledge sharing and ERP system usage in post-implementation stage. Computers in Human Behavior 33: 16-22.

Creswell, J. W. 2012. The selection of a research approach. In Research design: Qualitative, quantitative, and mixed methods approaches, ed. J. W. Creswell, 3-23. New York: SAGE.

Davis, F. 1989. Perceived usefulness, perceived ease of use, and user acceptance of information technology. MIS Quarterly 13(3): 319-340.

De Waal, B. and R. Batenburg. 2014. The process and structure of user participation: A BPM system implementation case study. Business Process Management Journal 20: 107-128.

Esteves, J. 2014. An empirical identification and categorization of training best practices for ERP implementation projects. Enterprise Information Systems 8: 665-683.

Galy, E. and M. Sauceda. 2014. Post-implementation practices of ERP systems and their relationship to financial performance. Information and Management 51: 310-319.

Ha, Y. and H. Ahn. 2013. Factors influencing the performance of enterprise resource planning (ERP) systems in the post-implementation stage. Behavior and Information Technology 33: 1065-1081.

King, P., A. Kvavik and J. Voloudakis. 2002. Enterprise resource planning systems in higher education. Centre for Applied Research Bulletin 22: 1-11.

Koch, C. 2002. The ABCs of ERP: Getting started with enterprise resource planning. http://www.citi. columbia.edu/B8210/read26a/supp1-07/theabcsoferp.pdf (Accessed 11 March 2017).

Koch, S. and K. Mitteregger. 2016. Linking customization of ERP systems to support effort: An empirical study. Enterprise Information Systems 10: 81-107.

Kwak, Y., J. Park, B. Chung and S. Ghosh. 2012. Understanding end users' acceptance of enterprise resource planning (ERP) system in project-based sectors. Transactions on Engineering Management 59: 266-277.

Maas, J., P. van Fenema and J. Soeters. 2014. ERP system usage: The role of control and empowerment. New Technology, Work, and Employment 29: 88-103.

Mahdavian, M. and F. Mostajeran. 2013. Studying key users' skills of ERP system through a comprehensive skill measurement model. International Journal of Advanced Manufacturing Technology 69: 1981-1999.

Markus, M. and J. Mao. 2004. Participation in development and implementation: Updating an old, tired concept for todays IS contexts. Journal of the Association for Information Systems 5: 514-544. http://citeseerx.ist.psu.edu/

McCracken, G. 1988. The long interview. Newbury Park, CA: Sage.

Mooketsi, R. 2015. An analysis of the effect of enterprise resource planning system on service delivery: A case study of the contemporary university. Master's dissertation, University of Derby, UK.

Ndungu, P. and J. Kyalo. 2015. An evaluation of enterprise resource planning systems implementation 
experiences for selected public universities in Kenya. International Journal of Scientific Research and Innovative Technology 2(2): 43-56.

Noaman, A. and F. Ahmed. 2015. ERP systems functionalities in higher education. Procedia Computer Science 65: 385-395.

Nwankpa, J. 2015. ERP system usage and benefit: A model of antecedents and outcomes. Computers in Human Behavior 45: 335-344.

Nwankpa, J. and Y. Roumani. 2014. Understanding the link between organizational learning capability and ERP system usage: An empirical examination. Computers in Human Behavior 33: 224-234.

O’Reilly, M. and N. Parker. 2012. Unsatisfactory saturation: A critical exploration of the notion of saturated sample sizes in qualitative research. Qualitative Research 13: 190-197.

Pishdad, A. and A. Haider. 2013. ERP institutionalization: Exploring the influential factors. Journal of Enterprise Information 26: 642-660.

Pollock, N. and J. Cornford. 2005. ERP systems and the university as a "unique" organisation. Information Technology and People 17(1): 31-52.

Poonam, G. and D. Agarwal. 2014. Critical success factors for ERP implementation in a Fortis hospital: An empirical investigation. Journal of Enterprise Information Management 27: 402-423.

Qureshi, M. and A. Abdulkhalaq. 2015. Increasing ERP implementation success ratio by focusing on data quality and user participation. International Journal of Information Engineering and Electronic Business 3: 20-25.

Rabaa'I, A. 2009. Identifying critical success factors of ERP systems at the higher education sector. http://www.bcs.org/upload/pdf/ewic_iict09_s5paper2.pdf (Accessed 9 February 2017).

Ram, J., D. Corkindale and M. Wu. 2015. Examining the role of organizational readiness in ERP project delivery. Journal of Computer Information Systems 55(2): 29-39.

Rose, L. 2011. Antecedents of end user satisfaction with an ERP system in a Transnational Bank. Journal of Information Systems and Technology Management 8(2): 389-406.

Rouhani, S. and A. Ravasan. 2013. ERP success prediction: An artificial neural network approach. Scientia Iranica 20: 992-1001.

Rueffler, C., J. Hermisson and G. Wagner. 2012. Evolution of functional specialization and division of labor. http://www.pnas.org/content/109/6/E326.full (Accessed 12 March 2017).

Sadki, B., J. Bengourram, H. Latrache and M. Mabrouki. 2015. Towards an organizational change management by an expert system. Journal of Control Science and Engineering 2: 79-90.

Schniederjans, D. and S. Yadav. 2013. Successful ERP implementation: An integrative model. Business Process Management Journal 19: 364-398.

Shanks, G., P. Seddon and L. Wilcocks. 2003. A comprehensive framework for assessing and managing the benefits of enterprise systems: The business manager's perspective. In Second wave enterprise resource planning systems: Implementing for effectiveness, ed. G. Shanks, P. Seddon and L. Wilcocks, 74-101. Cambridge: Cambridge University Press.

Swartz, D. and K. Orgill. 2012. Higher education ERP: Lessons learned. Using this framework for ERP could save your university millions of dollars. Educause Quarterly 2: 20-27.

Tambovceva, A. and T. Tambovceva. 2013. ERP system implementation: Benefits and economic effectiveness. In International Conference on Systems, Controls, Signal Processing and Informatics, ed. ICSC, 215-221. Greece, Rhodes Island, 16-19 July 2013, Rhodes Island. ISBN 9781618042040.

Teddlie, C. and F. Yu. 2007. Mixed methods sampling: A typology with examples. Journal of Mixed Methods Research 1(1): 77-100.

Tsai, W., P. Lee, Y. Shen and H. Lin. 2012. A comprehensive study of the relationship between enterprise resource planning selection criteria and enterprise resource planning system success. Information and Management 49: 36-46. 
Verdouw, C., R. Robbemond and J. Wolfert. 2015. ERP in agriculture: Lessons learned from the Dutch horticulture. Computers and Electronics in Agriculture 114: 125-133.

Weli, I. 2014. Manager satisfaction in using the enterprise resource planning (ERP) system and the managerial performance. Australasian Journal of Information Systems 18(3): 119-135.

Yelken, B. 2005. ERP system implementation: A case study. In A. S. Beko’s Master's dissertation. Ġstanbul Kültür University, Faculty of Engineering and Architecture, Department of Industrial Engineering, Turkey. http://passthrough.fw-notify.net/download/144044/, http://baharyelken. com/wp-content/uploads/2012/06/FPReportOutlineIndustrial.pdf (Accessed 03 April 2017).

Yin, R. 2014. Case study research design and methods. $5^{\text {th }}$ Edition. Thousand Oaks, CA: SAGE.

Zhang, S., P. Gao and Z. Ge. 2013. Factors impacting end-users' usage in ERP in China. Kybernetes 42: 1029-1043. 